Bangladesh J. Pl. Breed. Genet., 30(2): 29-34, 2017

\title{
GENETIC DIVERSITY OF RAPESEED (Brassica napus L.) GENOTYPES IN BANGLADESH
}

\author{
S. D. Joya, A. K. M. Shamsuddin and U. K. Nath \\ Department of Genetics and Plant Breeding \\ Bangladesh Agricultural University, Mymensingh 2202, Bangladesh.
}

\begin{abstract}
Genetic diversity in thirty eight traditional rapeseed genotypes was studied under favorable condition through Mahalanobis $\mathrm{D}^{2}$ statistic for yield and yield contributing characters. The genotypes were grouped into five clusters. The inter-cluster distances were higher than intracluster distances indicating wider genetic diversity among the clusters. The intra-cluster distances were lower in all the cases reflecting homogeneity of the genotypes within the clusters. Among the different cluster the genotypes of the cluster IV, III and I included were taller plant. The genotypes in the cluster III and IV had large size raceme. The genotypes in the cluster IV, III and V exhibited comparatively higher number of siliqua per raceme. Longer siliqua was noticed for the genotypes in the cluster III, IV and I. Higher number of seeds per siliqua noticed in clusters I, II and III. The genotypes of the cluster I and II produced bold size seed. The genotypes in the cluster V and I had high harvest index. The genotypes of the cluster III and I produced high seed yield per plant. Among the different cluster, the cluster III included the genotypes which had high yield, higher number of seeds per siliqua, longer siliqua, siliqua number per raceme and high plant height. Moreover these cluster displayed wide divergence with the genotypes of cluster V. The genotypes of the cluster $\mathrm{V}$ had the highest harvest index therefore selection of the parental material for crossing program for improvement of yield in rapeseed is suggested from these two clusters.
\end{abstract}

Keywords: Rapeseed (Brassica napus); genetic diversity; D $^{2}$ statistics; cluster analysis

\section{INTRODUCTION}

Rapeseed (Brassica napus), also known as rape, oilseed rape (and, in the case of one particular group of cultivars, canola), is a bright-yellow flowering member of the family Brassiceae (mustard or cabbage family), cultivated mainly for its oil-rich seed(Wikipedia, 2016).Rapeseed belongs to the family of Cruciferous under genus Brassica are most important oilseed crops, source of vegetable oil, widely grown oilseed crops of Bangladesh occupying 0.532 million ha of land and the production was 0.596 million MT (metric ton) with the yield of 1.12 MT (metric ton)/ ha in 2013-14(Wang\& Yin, 2014) It is now ranked first among oilseed crops in Bangladesh as well as the second largest oilseed crop in the world after soybean (FAO 2015).Domestic production of edible oil in Bangladesh mainly comes from mustard and sesame. Mustard and rapeseed seeds contain $42 \%$ oil, $25 \%$ protein (Kaul, 2006). In addition, its meal has 38$40 \%$ protein that has a complete profile of amino acids including lysine, methionine and cystine. The toxic content in Brassica napus are erucic acid and glucosinolate (Rashid, 2013). According to (Mondal et al., 2001) oil crops produce 0.16 million tons of edible oil every year as against the total requirements of 0.5 million tons for a population of 130 million in Bangladesh. The shortage of edible oil has become a chronic problem for the nation. 
To fulfill the requirement, the country has to import edible oils at the cost of huge amount of foreign exchange. The major activities of plant breeding are building up agene pool of variable germplasm, selection of individual from the gene pool and utilization of selected individual to evolve a superior variety (Zayaet et al., 2008). Genetic diversity refers to sum total of genetic variations found in a species or population. It is a prerequisite for the development of improved cultivars with wider adaptability and broad genetic base.

Diversity analysis greatly helps the breeder in identification and proper choice of parents for specific breeding objectives. To realize heterosis, genetically divergent parents are generally considered to be useful. In such crosses more variability could be expected in the resulting segregating progenies (Joseph et al., 1999). Precise information about the extent of genetic divergence on characters used for discrimination among the population is crucial in any crop improvement program, because selection of plants based on genetic divergence has become successful in several crops (Dubey et al., 2006).Genetic diversity is a powerful tool to determine the genetic discrimination among the genotypes which is used to select appropriate parents for hybridization to develop high yielding potential variety (khan2005). With the development of advanced biometrical techniques such as multivariate analysis based on the Mahalanobis (1936) statistics, quantification of divergence among the biological population and assessing the relative contribution of different components to the total divergence at intra and inter-cluster levels have now become possible. Such a study also permits to select the genetically diverse parents to obtain the desirable recombinant in the segregating generations upon crossing.

Hybridization is a common practice for combining the desirable characters of two or more lines or varieties into a single variety. In several cases, the progenies become far superior to the parents in vigor. Inclusion of more diverse parents (within a limit) is believed to increase the chances for obtaining stronger heterosis and gives broad spectrum of variability in segregating generations (Jessek et al., 2013). In addition, crossing in moderately diverse parents also showed maximum heterosis (Kumer, 2009). The necessity of principal component analysis (PCA), principal coordinate analysis (PCO), non-hierarchical clustering and canonical vector analysis (CVA) for measuring the degree of divergence has been established by several investigators in rapeseed and other crops (kakroo et al., 2001). The present study was, therefore undertaken to assess the extent of genetic diversity in 38 traditional Brassica napus L.genotypes. This will help in classifying those into clusters to select genotypes as prospective parents to develop transgressive segregants which will be ultimately used for developing modern variety (Ruksana et al,2005).

\section{MATERIALS AND METHODS}

The experiment was conducted with 38 genotypes of rapeseed in the experimental farm of the Department of Genetics and Plant Breeding, Bangladesh Agricultural University, Mymensingh. The experiment was laid out in Randomized Complete Block Design (RCBD) with three replications. Five plants were selected randomlyfromeachplotforcollectionofdataforyieldandyieldcontributingcharacters viz. plant height, raceme length, siliqua per raceme, siliqua length, seeds per siliqua, 1000 seed weight, harvesting index and yield/plants. The data were analyzed following principal component analysis (PCA) and Mahalanobis's (1936) generalized distance $\left(\mathrm{D}^{2}\right)$ extended by Rao (1952). Intra and inter cluster distances were calculated 
by the methods of (Singh,2000). All statistical analyses were carried out using MSTATC.

\section{RESULTS AND DISCUSSION}

Genetic divergence among the rapeseed was studied by estimating Mohalnobis'- $\mathrm{D}^{2}$ statistics which is presented in Table 1 . The $\mathrm{D}^{2}$ analysis grouped the 38 genotypes into five clusters. The cluster included group the genotypes in the different cluster shown in the Table 1 . The cluster I included 15 genotypes, which the highest followed by cluster III which contained 9 genotypes. Cluster IV and cluster III contained 7 and 4 genotypes respectively. The rest of three genotypes were included in the cluster (Hussain et al. 2008) studied the genetic divergence using Mahalnobis' $\mathrm{D}^{2}$ statistic in 40 diverse type of rapeseed and indicated that genotypes differed significantly for yield contributing characters.(Singh et al. 1997) studied genetic divergence through $\mathrm{D}^{2}$ statistic with 50 genotypes of B. napus growing in 12 environments based on 13 characters. They searched the clustering pattern and their inter and intra cluster distances. On the basis of stability, high yield and divergence among the genotypes, nine crosses were recommended as suitable for use in breeding programme.

Table 1. Distribution of 38 rapeseed genotypes indifferent cluster for various yield and yield contributing characters

\begin{tabular}{|c|c|c|}
\hline Cluster & $\begin{array}{c}\text { No. of } \\
\text { genotypes }\end{array}$ & Name of genotypes \\
\hline I & 15 & $\begin{array}{l}\text { Bina sarisha-14, Safal, Bina sarisha-6, Bari sarisha-7, Nap- } \\
\text { 0757, Nap-0957, Nap-0751, Nap-0726-2, Nap-0724-2, Nap- } \\
\text { 0760, Nap-0838, Bari sarisha-12, Agrani, Nap-0741-1 }\end{array}$ \\
\hline II & 4 & Bari sarisha-14, Nap-0740-2, Nap-0839, Tori-7 \\
\hline III & 9 & $\begin{array}{l}\text { Nap-0763, Nap-0721-1, Nap-0758-2, Bari sarisha-8, Bina } \\
\text { sarisha-3, Nap-0842-2, Nap-0824, Bina sarisha-5, Nap-0529 }\end{array}$ \\
\hline IV & 7 & $\begin{array}{l}\text { Bari sarisha-10, Bari sarisha-11, Bari sarisha-2, Bari sarisha- } \\
\text { 5, Nap-206×Nap-248, BC5897×BARI-8 Bari sarisha-13 }\end{array}$ \\
\hline V & 3 & Bari sarisha-3, Bari sarisha-6, Bari sarisha- 9 \\
\hline
\end{tabular}

Table 2. Average intra and inter cluster distances $D^{2}$ among 38 genotypes of rapeseed

\begin{tabular}{cccccc}
\hline Cluster & I & II & III & IV & V \\
\hline I & $\underline{\mathbf{3 8 0 . 1 5}}$ & & & & \\
II & 1214.47 & $\underline{\mathbf{3 9 2 . 3 3}}$ & & & \\
III & 590.93 & 1222.83 & $\underline{\mathbf{5 7 3 . 9 0}}$ & & \\
IV & 903.83 & 2542.81 & 1074.27 & $\underline{\mathbf{8 7 1 . 6 5}}$ & \\
V & 1008.15 & 1657.10 & 1602.06 & 1789.33 & $\underline{\mathbf{5 3 4 . 1}}$ \\
\hline
\end{tabular}

The bold and underline figures are intra-cluster distance.

The $\mathrm{D}^{2}$ values between and within the different clusters are shown in Table 4.5. There was genetic divergence within the different cluster group which ranged the $\mathrm{D}^{2}$ value 380 to 871. The cluster IV containing seven genotypes exhibited the highest amount of genetic divergence within the group. The inter-cluster distances $\left(D^{2}\right)$ were always higher than the intra-cluster distances. The distances between the cluster IV and V; III and V and II and V and II and IV were comparatively higher than the other inter-cluster 
distances. This means that genotypes of these clusters were more diversified for yield and yield contributing characters. Gupta, V.P. (2002) studied genetic divergence using the $\mathrm{D}^{2}$ statistics and canonical analysis among 25 genotypes of Brassica napus. They reported that genetic and geographical divergence was not related the genotypes were grouped into six clusters of which cluster I was the largest accommodating among these genotypes. The cluster VI had large genetic distance from the remaining clusters. The least variation was noticed between genotypes of the cluster I, entry indicating the closeness of the genotypes included in this cluster.

Contribution of the individual character towards divergence was presented in the Table 4.6. Table showed that harvest index contributed maximum to the genetic divergence and this was followed by 1000 seed weight and plant height. These means that these are the major characters which influenced the estimation of the $\mathrm{D}^{2}$ values. The rest amount of contribution towards the divergence was noticedthrough the characters. Siliqua length followed by siliqua per raceme, raceme length and seed yield per plant. Goswami et al., (2005). studied on some 19 genotypes of rapeseed (B. napus). They studied yield and yield contributing characters grouped the genotypes into 5 clusters with clusters I comprising these genotypes, clusters II and III 2 each and clusters IV and V one each. Test weight days to maturing and seed yield.

Table 3. Percent contribution of individual characters toward divergence

\begin{tabular}{lc}
\hline Characters & \% contribution toward divergence \\
\hline Plant height & 17.92 \\
Raceme length & 8.68 \\
Siliqua /raceme & 2.13 \\
Siliqua length & 0.28 \\
Seeds/Siliqua & 12.66 \\
1000 seed weight & 19.35 \\
Harvest index & 31.72 \\
Yield/plant & 7.26 \\
\hline
\end{tabular}

The cluster mean of the genotypes were estimated and presented character wise in Table 4. Among the different cluster the genotypes of the cluster IV, III and I included were taller plant. The genotypes in the cluster III and IV had large size raceme. The genotypes in the cluster IV, III and V exhibited comparatively higher number of siliqua per raceme. Longer siliqua was noticed for the genotypes in the cluster III, IV and I.

Table 4. The cluster means for yield and yield contributing characters in rapeseed

\begin{tabular}{lccccc}
\hline Characters & I & II & III & IV & V \\
\hline Plant height (m) & 110.41 & 83.25 & 106.52 & 126.77 & 98.75 \\
Raceme length & 46.21 & 33.53 & 51.58 & 51.46 & 37.21 \\
Siliqua/raceme & 28.98 & 22.09 & 31.38 & 39.62 & 32.57 \\
Siliqua length & 5.96 & 4.80 & 6.99 & 5.35 & 5.88 \\
Seed/ Siliqua & 21.27 & 18.14 & 20.74 & 14.19 & 16.55 \\
1000 seed weight & 3.63 & 3.60 & 3.02 & 3.17 & 3.06 \\
Harvest index & 32.10 & 18.42 & 21.98 & 29.03 & 49.56 \\
Yield/plant & 2.58 & 1.78 & 2.59 & 1.84 & 1.77 \\
\hline
\end{tabular}


Higher number of seeds per siliqua noticed in clusters I, II and III. The genotypes of the cluster I and II produced bold sizesize seed. The genotypes in the cluster V and I had high harvest index. The genotypes of the cluster III and I produced high seed yield per plant.

\section{CONCLUSION}

The present investigation on genetic diversity of rapeseed genotypes indicated a scope for improvement of grain yield through selection (Rameah et al, 2003)Genetic diversity in thirty eight traditional rapeseed genotypes was studied under favourable condition to assess the extent of genetic diversity which helps in classifying those into clusters to select genotypes as prospective parents to develop transgressive segregants that will be ultimately used for developing modern variety of rapeseed. (Dubey, R.N. 2006). Higher inter-cluster distances indicating indicating wider genetic diversity among the cluster also lower intra-cluster distances reflecting homogeneity of the genotypes within the clusters. In this study, the genotypes were grouped into five clusters. Among the different cluster the genotypes of the cluster IV (Bari sarisha-10, Bari sarisha-11, Bari sarisha-2, Bari sarisha-5, Nap-206×Nap-248, BC5897×BARI-8 Bari sarisha-13)III (Nap0763, Nap-0721-1, Nap-0758-2, Bari sarisha-8, Bina sarisha-3, Nap-0842-2, Nap-0824, Bina sarisha-5, Nap-0529)and I (Bina sarisha-14, Safal, Bina sarisha-6, Bari sarisha-7, Nap-0757, 2Nap-0957, Nap-0751, Nap-0726-2, Nap-0724-2, Nap-0760, Nap-0838, Bari sarisha-12, Agrani, Nap-0741-1) included were taller plant. The genotypes in the cluster III and IV had large size raceme. The genotypes in the cluster IV, III and V exhibited comparatively higher number of siliqua per raceme. Longer siliqua was noticed for the genotypes in the cluster III, IV and I. Higher number of seeds per siliqua noticed in clusters I, II and III. The genotypes of the cluster III and I produced high seed yield per plant. Among the different cluster, the cluster III included the genotypes which had high yield, higher number of seeds per siliqua, longer siliqua, siliqua number per raceme and high plant height. The genotypes of the cluster I and II produced bold size seed. The genotypes in the cluster $\mathrm{V}$ and I had high harvest index. Moreover these cluster displayed wide divergence with the genotypes of cluster $\mathrm{V}$. The genotypes of the cluster $\mathrm{V}$ had the highest harvest index therefore selection of the parental material for crossing program for improvement of yield in rapeseed is suggested from these two clusters.

\section{References}

AIS. 2015. Extending the rapeseedwith resynthesized Brassica napus L. I: Genetic diversity. Genet. Resour. Crop Evol. 59: 1441-1447.

Dubey, R. N. 2006. Genetic divergence in rapeseed. Indian J. Hered. 8(1-2): 33-40.

Falk K. C. 2009. Developing high yielding Brassica rapa cultivars with resistance to brown girdling root rot, blackleg, white rust, and rlubroot. Agriculture and AgriFood Canada, Saskatoon: Project Code 01.

FAO. 2013. Food and Agriculture Organization of the United Nations, FAOSTAT|C $\begin{array}{lllll}\text { FAO Statistics Division 2013|28 } & \text { February }\end{array}$ http://faostat3.fao.org/home/index.

Goswami, P. K. and R. K. Behl. 2005. Exploitation of heterosis and selection of superior combiners in Indian rapeseed. Department of Plant Breeding, CCS Haryana Agricultural University, Hissar-125 004, India. 26(1): 56-58.

Gupta, V. P. 2002. Interspecific hybridization among digenomic species of Brassica. Department of Genetics, Punjab Agricultural University, Ludhiana - 141004 , India. 27(2): 195-197. 
Hossain, A., R. P. Salini, B. P. S. Malik, and D. P. Singh. 2008. Variation for morphophysiological characters in genotypes of Indian rapeseed. Indian J. Agril. Sci. 57(4): 225-230.

Jesske T., B. Olberg, A. Schierholt and H. C. Becker. 2013. Resynthesized lines from domesticated and wild Brassica taxa and their hybrids with $B$. napus L.: genetic diversity and hybrid yield. Theor. Appl. Genet.126: 1053-1065.

Joseph, T. A., R. K. Birhman, S. K. Sood and J. Gopal. 1999. Genetic divergence in new potato genotypes. Journal of Indian Potato Association, 26(3\&4), p. 119-125.

Kakroo, P. and Kumar, S. 2001. Genetic determination of seed yield through its components in Indian rapeseed .Thesis Abstract, XVII-I: 82.

Kaul, A. K. and M. L. Das. 2006. Oil seeds in Bangladesh. Bangladesh-Canada Agric. Sectors Team-MOA, Bangladesh. p. 323.

Khan, F. A., Y. Muhammad and M. Ghulam. 2005. Correlation and factor wise contribution of the characters related to yield and quality of Brassica juncea $\mathrm{L}$. Department of Plant Breeding and Genetics, 7(2): 257-259.

Kumar, C. H. M. V., V. Arunachalam and P. S. K. Rao. 2009. Ideotype and relationship between morpho-physiological characters and yield in Indian rapeseed $(B$. napus). Indian J. Agric. Sci. 66(11): 14-17.

Mondal MRI, M. A. Hossain, M. H. Ali and F. Begum. 2001. Oil seed production in Bangladesh: Constrains and opportunities. A paper presented on the 7th Biennial Agronomy Conference on 18th April 2001. Bangladesh Society of Agronomy P. 45.

Rameah, V., A. Rezai and G. Saeidi. 2003. Estimation of genetic parameters for yield, yield components and glucosinolate in rapeseed (Brassica napus L.). pp. 5(3/4): 143-151.

Rashid A. 2013. "Rapeseed," Pakistan Agricultural Reseach Council.: http://www.old.parc.gov.pk/1sub-divisions/narccsi/csi/rapeseed.html.

Ruksana, A., Y. Muhammad, J. Muhammad, H. Mumtaz, N. Nazakat and A. Amir. 2005. Adaptation and yield potential of different genotypes of rapeseed and mustard under agro-climatic conditions of Bahawalpur (Pakistan). Agriculture. 7(4): 609611.

Singh, B. D. 2000. Plant Breeding. Klyani Publishers, New Delhi. pp. 574-597.

Singh, R. K. and B. D. Chudhary. 1985. Biometrical methods in quantitative genetic analysis. Kalani Publishers, New Delhi, India. p.

Singh, R. P., D. P. Singh and B. D. Chaudhary. 1997. Morpho-physiological variation in Indian rapeseed. 3(1): 26-31.

Thakra, N. K., T. P. Yadav, Kumar, P. A. Singh and N. Chandra. 2004. Association analysis. for quantitative traits in Indian rapeseed. Cruciferae Newsletter. 21: 105-106.

Wikipedia. 2016. Brassica. http://en.wikipedia.org/ wiki/Brassica.

Yadava, D. S., A. Prasad and N. D. Singh. 2006. Genetic divergence for fruit yield and its components in rapeseed. 17(3): 265-271.

Yadava, T. P. and P. Kumar. 2003. Association of seed yield with some quality attributes of rapeseed. Indian J. Agril. Sci. 53(7): 605-606.

Zayaet, T., J. Bieniek, R. Witkoweez and M. Gierdziewiez. 2008. Individual share of field components in winter oilseed rape yield formation. Akademia Rolniezaw Kraikowie, Poland. 19(2): 413-422. 